\title{
CONECTANDO O INVESTIMENTO SOCIAL PRIVADO AOS NEGÓCIOS DE IMPACTO AMBIENTAL: O PAPEL DAS ORGANIZAÇÕES INTERMEDIÁRIAS
}

\author{
Julio Nunes Campos
}

\begin{abstract}
// resumo
Este artigo busca analisar o que os mapeamentos sobre negócios de impacto revelam sobre a relação entre o investimento social privado e as questões ambientais. Para isso, são avaliados os portfólios de organizações intermediárias que já apoiaram negócios de impacto ambiental com o fim de identificar para quais desafios ecológicos estão sendo direcionados os investimentos de impacto no Brasil. O método consiste na análise do portfólio de todas as organizações listadas no Guia 2.5, do Instituto Quintessa, para se identificar os negócios de impacto que passaram por algum processo de validação. A análise dos dados secundários indica que os segmentos de agropecuária e energia estão entre os que mais receberam aporte dessa modalidade de capital, enquanto a gestão de resíduos é representada pelo maior número de empresas. Segmentos pouco representados, como educação ambiental, gestão hídrica, logística e mobilidade carecem de levantamentos setoriais específicos para conclusões mais precisas.
\end{abstract}

| Palavras-chave: investimento de impacto | investimento social privado | negócio de impacto ambiental | organização intermediária. 


\section{OS ARTIGOS GIFE}

A série Artigos GIFE publica reflexões e análises de pesquisadores brasileiros de diferentes áreas do saber com o objetivo de estimular, ampliar e disseminar a produção de conhecimento qualificado sobre o campo da filantropia, do investimento social privado e da sociedade civil no Brasil.

A partir da premissa de que a produção de conhecimento sobre esses temas tem um papel fundamental na expansão, diversificação e qualificação da ação pública pela sociedade, a iniciativa também pretende contribuir para ampliar as conexões entre o setor, as universidades e os centros de pesquisa, promovendo e apoiando o envolvimento de novos atores com a temática e a circulação ampliada de ideias em torno dela.

Este texto integra a quarta edição dos Artigos GIFE, que propõe a publicação mensal de artigos selecionados por meio de chamada pública e convite a autores especialistas em temáticas específicas e relevantes para o setor, buscando apoiar e fomentar a produção de conhecimento sobre o investimento social no Brasil.

\section{O GIFE}

O Grupo de Institutos Fundações e Empresas (GIFE) é uma organização sem fins lucrativos que reúne associados de origem empresarial, familiar ou independente que investem em projetos de interesse público. Criado em 1989 como grupo de troca e colaboração e institucionalizado em 1995 por 25 organizações, tornou-se referência no campo da filantropia e do investimento social privado no Brasil.

Nesses mais de 20 anos de atuação, tem contribuído para o fortalecimento de práticas e ações a serviço do bem comum no país, trabalhando para expandir, qualificar e fortalecer o investimento social privado, diversificar e ampliar atores e recursos, criando referências e estimulando boas práticas de gestão, bem como articulando o setor com a sociedade e a agenda pública. Atualmente, o GIFE reúne mais de 150 associados que, somados, aportam mais de R\$ 3 bilhões por ano em projetos próprios e no apoio a projetos de terceiros. 


\section{artigos \\ GIFE}

\section{INTRODUÇÃO}

Para avaliar o cumprimento de objetivos ecológicos das organizações sociais, é necessária a disseminação de um volume cada vez maior de dados e informações sobre o setor. As pautas ambientais, em especial, carecem de análises referentes ao estado de degradação do meio ambiente para identificar as possibilidades que se abrem para iniciativas que buscam contribuir com a reversão desse processo. Nesse sentido, os negócios de impacto ambiental se situam entre as propostas de agentes econômicos que buscam combinar o propósito socioambiental das organizações sociais com o objetivo econômico de empresas tradicionais. Levantamentos publicados por organizações de apoio permitem caracterizar o panorama desses empreendimentos no país, que crescem a cada ano. No entanto, faltam esforços de sistematização dessas informações para a construção de diagnósticos para empreendedores e investidores interessados em mobilizar recursos privados em prol de contribuições ecológicas de interesse público.

O conceito de negócio de impacto aqui adotado se baseia nas diretrizes da Aliança pelos Investimentos e Negócios de Impacto, que lista quatro critérios mínimos para caracterizá-los: intencionalidade de resolução de um problema social e/ ou ambiental; solução de impacto como atividade principal do negócio; busca de retorno financeiro, operando pela lógica de mercado; e compromisso com o monitoramento do impacto gerado (ICE e PIPE SOCIAL, 2019). Sendo assim, o conceito de negócio de impacto ambiental é empregado para se referir aos empreendimentos que têm na sua atividade principal a intenção de reduzir, neutralizar ou reverter um impacto ambiental negativo (CAMPOS e COMINI, 2019). Como não é escopo deste trabalho avaliar individualmente a adesão dos casos aos quatro critérios, são analisados somente empreendimentos validados por organizações de suporte ao setor. O objetivo é identificar a conexão entre o negócio de impacto, o recurso nele investido e o problema ambiental que se busca endereçar.

As duas primeiras seções sintetizam os principais resultados dos mapeamentos sobre negócios de impacto publicados entre 2017 e 2019, para quantificar e caracterizar aqueles que atuam com questões ambientais. Em seguida, busca-se fazer o mesmo com o panorama do investimento social privado. A seção 4 apresenta uma proposta metodológica para o levantamento de negócios de impacto com base no portfólio das organizações intermediárias. Por fim, a seção 5 discute os resultados da aplicação do método aos negócios de impacto ambiental, comparando-os com aqueles identificados na revisão bibliográfica. 


\section{MAPEANDO OS NEGÓCIOS DE IMPACTO AMBIENTAL NO BRASIL}

Os mapeamentos de negócios de impacto da Pipe Social revelam um aumento expressivo no número de empreendimentos que buscam contribuir com questões ambientais. O levantamento de 2017 classificou 133 empresas no eixo de atuação "tecnologias verdes", que inclui todos os tipos de negócios com impacto ambiental (PIPE SOCIAL, 2017). Em 2019 cadastraram-se 461 empresas na mesma categoria, dobrando a representação do eixo em relação ao total, de 23\% para 46\% (PIPE SOCIAL, 2019). No que diz respeito à consideração dos objetivos do desenvolvimento sustentável (ODS) destacam-se o objetivo 12, produção e consumo sustentável (39\% do total), o 11, cidades e comunidades sustentáveis (37\%), o 13, ação contra mudança global do clima (24\%) e o 6, água potável e saneamento (10\%). Objetivos relacionados com a conservação da biodiversidade, o 14, vida na água e o 15 , vida na terra, representam $4 \%$ e $5 \%$, respectivamente.

Uma questão relevante é o segmento de atuação dessas iniciativas. A chamada de Bons Negócios pelo Clima tem como objetivo mapear e fomentar negócios que geram impacto positivo no clima. As iniciativas inscritas foram divididas em categorias: alimentação, energia, florestas, gestão da água, gestão de resíduos, logística e uso do solo. Apesar da diferença no número de inscrições de uma edição para outra (de 315, em 2018, para 179, em 2020), as distribuições permaneceram semelhantes: em ambas, a categoria mais representada foi gestão de resíduos, com $35 \%$ do total. Agropecuária, energia e florestas aparecem em seguida, com cerca de $15 \%$ cada (CLIMATE VENTURES, 2018, 2020).

Outro levantamento buscou identificar as startups de cleantech, ou seja, aquelas que atuam com tecnologias limpas. Apesar de o estudo não tratar exclusivamente dos negócios de impacto, diversas organizações de suporte ao setor se situam entre os colaboradores da pesquisa. São listadas 136 empresas, classificadas com base na taxonomia da consultoria Kachan \& Co., que propõe a divisão das cleantechs em agricultura, água, ar e meio ambiente, armazenamento de energia, eficiência, energia limpa, indústria limpa e transporte (KACHAN, 2013). A divisão revela que a maior parte dessas empresas atua no segmento de energias renováveis (41\%), seguido por ar e meio ambiente (32\%) (FEITOSA et al., 2019).

As problemáticas ambientais listadas pelos respondentes também evidenciam a concentração e os desafios regionais dos negócios de impacto. Mais da metade das empresas dos levantamentos citados até aqui situam-se na região Sudeste, sobretudo no estado de São Paulo. Isso se reflete na área de atuação: os mapeamentos da Climate Ventures revelam que a gestão de resíduos, um desafio ecológico característico dos grandes centros urbanos, é o que mais se busca solucionar no Sudeste. Nas regiões Sul e Nordeste predominam negócios que atuam no segmento de energia (CLIMATE VENTURES, 2018). Não à toa, em 2018 as duas regiões responderam por 99\% da geração de energia eólica e 60\% de energia solar no Brasil (EPE, 2019, p. 152).

Nas zonas rurais, o setor agropecuário ainda dispõe de poucas informações sobre a participação de negócios de impacto em suas atividades. Um mapeamento sobre agricultura de impacto identificou 40 iniciativas de agricultura climate-smart (DISSEMOND et al., 2018), que pode ser definida como aquela composta por três pilares: aumento sustentável de produtividade e renda; adaptação e resiliência às mudanças climáticas e esforço de redução de gases do efeito estufa (FAO, 2013, p. 9). A agenda dos negócios de impacto no que diz respeito à governança inclusiva com os interesses da comunidade (COPPOLA e SANT'ANA, 2019, p. 117) é uma relevante abordagem para a realidade da agricultura familiar. Nesse contexto, o resultado do Desafio Conexsus 2018 consiste em uma lista de 1.040 associações de produtores e cooperativas das cadeias de alimentação. O recorte revela uma distribuição geográfica mais diversa do que no caso de negócios de impacto, com iniciativas em todos os biomas brasileiros (CONEXSUS, 2019).

Por fim, a maior parte dos negócios de impacto da região Norte atua de alguma forma com a floresta Amazônica. O programa de aceleração Parceiros pela Amazônia também teve um aumento no número de empresas inscritas, de 81 para 200, no biênio 2018-2019, concentradas no Amazonas e no Pará. 


\section{CARACTERISTICAS DOS NEGÓCIOS BRASILEIROS DE IMPACTO AMBIENTAL}

Uma vez identificadas a distribuição e a segmentação dos negócios de impacto, essa análise se volta para as características comuns a esse tipo de empreendimento, com base em dois indicadores-chave: faturamento bruto e fase de maturidade do negócio.

Segundo a lei complementar 123 (BRASIL, 2006), microempresa é aquela com faturamento inferior ou igual a 360.000 reais anuais, enquanto empresa de pequeno porte fatura entre 360.000 e 4.800 .000 reais. Segundo esses critérios, pode-se afirmar que pelo menos um terço dos negócios de impacto ambiental são microempresas (Tabela 1). Devido às escolhas metodológicas dos mapeamentos analisados, que agruparam os negócios na faixa dos 500.000 reais, não é possível discernir com exatidão a proporção de empresas de pequeno porte. Ainda assim, pode-se estimar que ao menos $15 \%$ dos casos se enquadram nesse critério ${ }^{1}$.

\section{Tabela 1 - Faixa de faturamento dos negócios de impacto mapeados no Brasil}

\begin{tabular}{|c|c|c|c|c|c|c|c|c|}
\hline \multirow[b]{2}{*}{ Levantamento } & \multirow[b]{2}{*}{$\begin{array}{l}\text { Organização } \\
\text { responsáve|(1) }\end{array}$} & \multirow[b]{2}{*}{ Ano } & \multirow[b]{2}{*}{$\begin{array}{l}\text { N. de } \\
\operatorname{casos}^{(2)}\end{array}$} & \multicolumn{5}{|c|}{ Faturamento (\%) } \\
\hline & & & & $\begin{array}{l}\text { Sem } \\
\text { fatura- } \\
\text { mento }\end{array}$ & $\begin{array}{l}\text { Até } 100 \\
\text { mil reais }\end{array}$ & $\begin{array}{l}101 \text { a } \\
500 \text { mil } \\
\text { reais }\end{array}$ & $\begin{array}{l}501 \text { mil a } \\
1 \text { milhão } \\
\text { de reais }\end{array}$ & $\begin{array}{l}\text { Mais de } \\
1 \text { milhão } \\
\text { de reais }\end{array}$ \\
\hline \multirow{2}{*}{$\begin{array}{l}\text { Chamada de Bons } \\
\text { Negócios pelo Clima }\end{array}$} & \multirow{2}{*}{$\begin{array}{l}\text { Climate } \\
\text { Ventures }\end{array}$} & 2018 & 315 & 40 & 33 & 12 & 3 & 7 \\
\hline & & 2019 & 179 & 32 & 40 & 11 & 11 & 5 \\
\hline \multirow{2}{*}{$\begin{array}{l}\text { Mapa de Negócios } \\
\text { de Impacto Social }+ \\
\text { Ambiental }\end{array}$} & \multirow{2}{*}{ Pipe Social } & 2017 & 176 & 32 & 37 & 11 & 6 & 13 \\
\hline & & 2019 & 466 & 45 & 32 & 10 & 4 & 9 \\
\hline $\begin{array}{l}\text { Mapeamento do } \\
\text { Ecossistema de } \\
\text { Cleantech }\end{array}$ & $\begin{array}{l}\text { ABStartups, } \\
\text { COPPE/UFRJ, } \\
\text { EDP Brasil, } \\
\text { FGVces }\end{array}$ & 2019 & 136 & - & 41 & 23 & 13 & 18 \\
\hline $\begin{array}{l}\text { Panorama dos Negócios } \\
\text { Comunitários }\end{array}$ & Conexsus & 2019 & 1.040 & 15 & 47 & 22 & 9 & 8 \\
\hline $\begin{array}{l}\text { Retrato dos Pequenos } \\
\text { Negócios Inclusivos e de } \\
\text { Impacto }\end{array}$ & $\begin{array}{l}\text { PNUD, } \\
\text { SEBRAE }\end{array}$ & 2017 & 837 & 48 & 39 & 8 & & 6 \\
\hline
\end{tabular}

Fonte: Climate Ventures (2018, 2019); Feitosa et al. (2019); Pipe Social (2017, 2019); PNUD e SEBRAE (2017).

Notas:

(1) Associação Brasileira de Startups (ABStartups); Instituto Alberto Luiz Coimbra de Pós-Graduação e Pesquisa de Engenharia (COPPE/UFRJ); Centro de Estudos em Sustentabilidade da Fundação Getulio Vargas (FGVces); Programa das Nações Unidas para o Desenvolvimento (PNUD); Serviço Brasileiro de Apoio às Micro e Pequenas Empresas (SEBRAE).

(2) Pode haver sobreposição de casos.

Outra característica chama a atenção: o aumento no número de empresas sem faturamento nos mapeamentos da Pipe Social. Mais de 200 empresas do eixo de atuação “tecnologias verdes” ainda não tinham obtido receita, enquanto 84 se encontravam na fase de ideia, ou seja, ainda não haviam saído do papel. A proporção de empresas sem faturamento foi a única que cresceu entre 2017 e 2019, o que requer atenção no suporte de empresas em fase embrionária por organizações de apoio, como incubadoras. $\mathrm{O}$ quadro do faturamento também é explicado pelo grau de maturidade dos empreendimentos, já que a maior parte deles se encontra nos estágios iniciais de organização do negócio: ideia, protótipo, piloto, validação e mínimo produto viável.

1 Devido às diferenças na classificação dos faturamentos mais altos, foram agrupadas empresas com receita acima de 1 milhão. No levantamento do SEBRẢE/PNUD, as faixas de faturamento são divididas em até 60.000, 60.000 a 150.000 , 150.000 a 600.000 e acima de 600.000 reais. Situação semelhante ocorre com o panorama do Desafio Conexsus, que as agrupa entre 600.000 e 1.200 .000 reais. Esses casos foram enquadrados na tabela nas faixas mais próximas, para efeito de comparação. 
Deve-se enfatizar que essas constatações condizem com o contexto das micro e pequenas empresas brasileiras. Segundo um levantamento do SEBRAE que contou com 1.887 empreendedores, foi possível constatar que $93 \%$ dos entrevistados se diziam comprometidos com a sustentabilidade ou aos ODS de alguma forma. Trata-se de uma estimativa otimista, na medida em que revela uma tendência à adesão ao conceito de sustentabilidade por uma parcela da economia responsável por $27 \%$ do produto interno bruto brasileiro (SEBRAE, 2018) e representativa da realidade dos negócios de impacto ambiental. Isso pode ser constatado pela publicação do retrato dos pequenos negócios inclusivos e de impacto, com resultados semelhantes aos já constatados até aqui: alta proporção de empresas sem faturamento, em estágio de ideação/validação e com concentração regional no Sudeste (PNUD e SEBRAE, 2017).

\section{PANORAMA BRASILEIRO DO INVESTIMENTO SOCIAL PRIVADO EM NEGÓCIOS DE IMPACTO AMBIENTAL}

Do lado do investimento, é notório o aumento no volume de aplicações financeiras em negócios de impacto no Brasil. Levantamentos realizados desde 2013 permitem acompanhar a evolução dos valores: estima-se que, de 2003 a 2013, foram 76,7 milhões de dólares em 68 negócios de impacto (ANDE e LAVCA, 2014, p. 16). Entre 2014 e 2015, foram 68,8 milhões de dólares, com 45\% desse montante voltado para a agricultura (ANDE e LAVCA, 2016, p. 65). Finalmente, no biênio 2016-2017 foram investidos 131 milhões de dólares, 22\% dos quais convertidos em iniciativas com impacto ambiental, liderados pelo setor energético e seguido por agricultura, água e saneamento, gestão de resíduos e manejo florestal (ANDE e LAVCA, 2018, p. 22).

Os dados do Censo GIFE 2018, respondido por 133 associados, também indicam um crescimento no âmbito do investimento social privado: de 16 milhões de dólares em 2016, para 24,4 milhões em 2017, e 30 milhões em 2018 (GIFE, 2017 e 2019). ${ }^{2}$ Um quarto dos entrevistados afirmou repassar recursos para negócios de impacto e organizações intermediárias, com a maior parte desse montante (71\%) aplicado por empresas (GIFE, 2019, p. 142). Dentre os instrumentos financeiros mais utilizados, destacam-se dívidas conversíveis, empréstimos tradicionais e participação acionária (ANDE e LAVCA, 2018; PIPE SOCIAL, 2020).

Os setores com impacto ambiental beneficiados com maior volume de investimentos foram energia e agricultura (ANDE e LAVCA, 2014, 2016, 2018). Mais da metade dos entrevistados em 2018 afirmaram estar comprometidos com alguma ODS relacionada com a biosfera, com destaque para a ação contra a mudança climática global (ANDE e BOTICÁRIO, 2018, p. 6). Destaca-se, ainda, um expressivo número de operações (seis) na temática conservação da biodiversidade em 2018 (ANDE e LAVCA, 2018). Quanto à agropecuária, estimam-se investimentos de impacto no valor de 39,1 milhões de dólares em iniciativas do tipo climate-smart no Brasil no período 2014-2017 (DISSEMOND et al., 2018, p. 20).

No que diz respeito às possíveis fontes de financiamento de projetos associados às ODS de temática ambiental, também predominam recursos privados. O trabalho de Castro et al. (2019) identificou que o ODS 13, ação contra a mudança global do clima e o 15, vida terrestre, são os que dispõem do maior número de fontes financiadoras. Quanto ao tipo de instrumento financeiro, a maior parte deles (68\%) é composto por empréstimos, enquanto nos ODS ambientais predominam recursos "não reembolsáveis". Isso pode indicar menor presença de atividades rentáveis nesses casos (CASTRO et al., 2019, p. 40), além de ser um tipo de financiamento pouco adequado para a fase de criação do negócio (OLIVEIRA FILHO e IZZO, 2019, p. 191), situação em que se encontra parcela expressiva dos negócios de impacto ambiental.

Do lado da demanda por capital, 85\% dos negócios mapeados em 2019 afirmaram estar captando recursos. As quantias demandadas variam, apesar de mais de três quartos das empresas afirmarem buscar valores de até 1 milhão de reais (PIPE SOCIAL, 2019, p. 25). No entanto, faltam investimentos entre 250.000 e 1.000 .000 de reais (ANDE e LAVCA, 2018, p. 24). Reconhece-se que, no ecossistema de impacto, sobram recursos de investidores e demanda de capital por empreendedores (PIPE SOCIAL, 2020, p. 16). Logo, avaliar como a conexão entre eles vem sendo conduzida por atores de suporte ao setor é uma oportunidade de traçar um panorama da interação entre a tese de impacto ambiental, o modelo de negócio e o agente financiador no contexto econômico brasileiro.

2 Valores originais em reais. A conversão em dólar foi feita com base na cotação do último dia do ano. 


\section{CONSIDERAÇÕES METODOLÓGICAS}

As organizações intermediárias foram definidas pelo decreto 9.244 (BRASIL, 2019), que instituiu a Estratégia Nacional de Investimentos e Negócios de Impacto (ENIMPACTO), como organizações que facilitam e apoiam a conexão entre a oferta de investidores, doadores e gestores e a demanda de capital por negócios que geram impacto socioambiental. Esses atores podem ser classificados nas seguintes áreas de atuação: conhecimento e informação; gestão e acesso a investidores; monitoramento, avaliação e certificação; recursos e serviços financeiros (MARCHESIN et al., 2015). Exemplos incluem aceleradoras, fundos de investimento, incubadoras e institutos. Do ponto de vista institucional, as organizações intermediárias desempenham um papel normativo: indicam, em suas áreas de atuação, os empreendimentos e investidores alinhados com princípios consensuais acerca dos negócios de impacto. Sendo assim, a avaliação do portfólio dessas organizações, ou seja, a análise de quais negócios elas já apoiaram, pode fornecer indicadores de como e para quem os recursos estão sendo alocados dentro dos diferentes segmentos de impacto ambiental. Uma vantagem desse método é a pressuposição de algum tipo de validação: afinal, sem uma proposta organizacional madura e um propósito socioambiental, esses empreendimentos não teriam sido escolhidos.

Uma publicação que reúne programas de diversas organizações intermediárias, o Guia 2.5, publicado pelo Instituto Quintessa (2017), tem a proposta de listar 34 iniciativas de suporte ao desenvolvimento de negócios de impacto. Os programas foram selecionados a partir de quatro critérios: abertura da inscrição para empreendedores; foco explícito em negócios de impacto; foco principal no suporte ao desenvolvimento de negócios de impacto; e recorrência ou perspectiva de comunidade. Com base nisso, este artigo identifica quais empreendimentos já fizeram parte dessas iniciativas, analisando o portfólio dos programas listados no Guia 2.5, para classificar as empresas em categorias ambientais e os programas em estágios de maturação do negócio, de acordo com a divisão que consta no Guia: 1) fase das ideias; 2) validação: foco no cliente; 3) validação: foco no produto; 4) validação: foco no mercado; 5) refinamento do modelo de negócio; e 6) expansão (QUINTESSA, 2017, p. 6). A segmentação foi realizada de acordo com a atividade principal das empresas, enquadradas em uma das categorias a seguir: agropecuária, alimentação, educação ambiental, energia, florestas, gestão da água, gestão de resíduos, logística e mobilidade e produtos verdes. Algumas empresas participaram de diversos programas e são citadas mais de uma vez. O mesmo ocorre com aquelas que atuam em múltiplos segmentos ambientais. Os empreendimentos foram identificados por fontes secundárias: os websites das organizações intermediárias. Os programas listados no Guia 2.5 que não apoiaram algum negócio com impacto ambiental ou não dispunham de uma lista atualizada de empresas em seus websites não foram incluídas.

A categoria de alimentação foi separada de agropecuária para diferenciar comercialização e produção de alimentos. A primeira contempla atividades que lidam com o alimento do lado de fora da porteira: do transporte à comercialização, incluindo negócios que assumem o papel de conexão entre produtores e consumidores. Similarmente, os produtos alimentícios provenientes de extrativismo vegetal foram enquadrados na categoria florestas. A educação ambiental compreende negócios que atuam com programas educacionais voltados para a conservação do meio ambiente. A categoria energia diz respeito aos que atuam com energias renováveis, além de soluções que buscam melhorar a eficiência do regime energético baseado em carbono. Os negócios contemplados pela categoria gestão de resíduos atuam com estratégias relacionadas aos 4R - de reciclar, recuperar, reduzir e reutilizar. A categoria associada ao uso da água também apresenta grande diversidade de iniciativas: nela, cabe qualquer estratégia de negócio relacionada com gestão hídrica. A categoria de logística e mobilidade contempla empreendimentos que oferecem soluções de baixo impacto ambiental no suprimento e distribuição de produtos, além daqueles que visam minimizar os impactos associados à mobilidade urbana. Por fim, foram considerados produtos verdes aqueles cujos processos produtivos foram projetados para mitigar o impacto ambiental do seu ciclo de vida.

\section{CONECTANDO A OFERTA DE CAPITAL COM A SOLUÇÃO AMBIENTAL}

Com base nesse recorte, foram identificados 137 negócios de impacto ambiental, apoiados por 24 organizações intermediárias em 18 estados brasileiros (Quadro 1, p. 09).

A categoria alimentação identificou eixos de atuação relacionados com alimentação saudável, combate ao desperdício de alimentos e incentivo à agricultura familiar. A categoria de agropecuária, por outro lado, engloba atividades de produção de diferentes tipos de alimentos - exemplos incluem café, carne suína, chocolate, leite, peixes - em diversos biomas, além de sistemas de gestão e infraestrutura destinados a atividades agrícolas. 
A categoria de florestas, por sua vez, inclui modelos de negócio que atuam com produtos da biodiversidade como açaí, cacau, cupuaçu e jaborandi - e, além de atividades agroextrativistas, também projetos de conservação, manejo e restauração florestal.

No segmento relacionado com a educação ambiental, as estratégias identificadas incluem a implementação de programas educacionais escolares e corporativos, portais online e programas de recompensas para estimular o comportamento pro-ambiental.

No que se refere aos empreendimentos do setor energético, os negócios identificados podem ser divididos em três modalidades: biomassa, energia solar e sistemas de eficiência energética. Esse resultado se assemelha à realidade das cleantechs: dentre as empresas que atuam com energias renováveis, $63 \%$ apresentam soluções fotovoltaicas, seguidas por biomassa (39\%) (FEITOSA et al., 2019). Levando-se em consideração a expressividade do setor energético em investimentos de impacto, o recorte adotado permite afirmar que as soluções que envolvem energias renováveis se situam entre as propostas ambientais mais beneficiadas no que diz respeito ao aporte de capital (ANDE e LAVCA, 2016, 2018).

Outro segmento de destaque, o de gestão de resíduos, foi representado pelo maior número de empreendimentos. Ainda assim, a despeito do alto número de iniciativas, trata-se de um segmento que recebeu poucos investimentos de impacto (ANDE e LAVCA, 2018, p.22). Os negócios identificados atuam, além dos 4R, com assessoria na gestão de resíduos corporativos, municipais e residenciais. A diversidade de propostas reflete as possibilidades de modelos de negócio da economia circular que, segundo Stahel (2016), podem ser divididos em duas categorias: aqueles que visam estender a vida do serviço dos materiais por meio de atividades como reparos e remanufaturas; e aqueles que transformam o resíduo em novos produtos e serviços, como no caso da reciclagem.

Na categoria de gestão da água, as empresas atuam em diferentes frentes, mas permanecem sub-representadas quando comparadas às outras. Os casos identificados atuam, além de aspectos relacionados com a gestão hídrica em si, com sistemas de monitoramento climático e tratamento de água. Por outro lado, a categoria logística e mobilidade aparenta ser a mais uniforme: quase todas as iniciativas mapeadas incluem o uso de bicicletas em alguma forma, seja na comercialização de bicicletas elétricas ou em serviços de entrega por ciclistas em ambientes urbanos. A exceção é um serviço de monitoramento logístico rodoviário e fluvial na floresta amazônica. Essas empresas poderiam igualmente ser enquadradas em levantamentos sobre cidades sustentáveis, o que evidencia a sobreposição da problemática urbana com temas ecológicos.

Finalmente, na categoria de produtos verdes, foram identificados itens como cosméticos, papéis, produtos de limpeza, roupas e utensílios de cozinha. No que diz respeito à estratégia de sustentabilidade, duas foram mais frequentes: a biodegradabilidade dos produtos e o emprego de resíduos na produção.

\section{CONSIDERAÇÕES FINAIS}

Os levantamentos sobre o panorama dos negócios de impacto ambiental revelam que esse mercado tem crescido no Brasil, tanto no número de empresas quanto no volume de investimentos. Também apontam para o desafio da atuação das organizações intermediárias no alinhamento das expectativas dos investidores com a realidade das micro e pequenas empresas. No âmbito do investimento, pela disponibilidade de instrumentos financeiros adequados para a fase de maturidade e o segmento de atuação do negócio; e, no lado do empreendedor, pela capacidade de articulação frente aos desafios da sustentabilidade ambiental e financeira.

Os problemas ambientais que os negócios de impacto buscam endereçar refletem as peculiaridades ecológicas das regiões brasileiras. Os mais beneficiados com investimentos de impacto pertencem a segmentos de mercado mais tradicionais, como os setores agropecuário e energético. Ainda assim, a maior parte deles se debruça sobre o uso responsável do resíduo, sobretudo no Sudeste. As categorias que dependem mais diretamente dos serviços ecossistêmicos, como agropecuária, alimentação e florestas, apresentam uma grande diversidade de produtos e estratégias de atuação. Sendo assim, esses casos se beneficiariam de levantamentos setoriais específicos aos desafios do segmento, especialmente em casos ainda pouco explorados por empreendedores, que também incluem os setores relacionados com a conservação da biodiversidade, educação ambiental, gestão da água, logística e mobilidade. 
Quadro 1 - Negócios de impacto ambiental apoiados por organizações intermediárias

\begin{tabular}{|c|c|c|c|c|c|c|c|c|c|c|c|c|c|c|}
\hline Organização & Iniciativa & Principal suporte & $\begin{array}{lll} & \text { Está } \\
1 & 2 & 3\end{array}$ & tágio (") & & Agropecuária & Alimentação & $\begin{array}{l}\text { Educacãão } \\
\text { ambiental }\end{array}$ & Energia & Florestas & Gestão da água & $\begin{array}{l}\text { Gestão de } \\
\text { resíduos }\end{array}$ & $\begin{array}{l}\text { Logísticae } \\
\text { mobilidade }\end{array}$ & $\begin{array}{l}\text { Produtos } \\
\text { Verdes }\end{array}$ \\
\hline Artemísia & Aceleradora & $\begin{array}{l}\text { Captação e } \\
\text { treinamento }\end{array}$ & & $x \quad x$ & $x \quad x$ & Silo Verde & $\begin{array}{l}\text { Gastromotiva; } \\
\text { Sementes de } \\
\text { Paz; } \\
\text { Sumá. }\end{array}$ & So+ma & $\begin{array}{l}\text { Green Ant; } \\
\text { Solstar. }\end{array}$ & - & - & Molécoola & - & - \\
\hline Bankoo & Magnuss & $\begin{array}{l}\text { Desenvolvimento } \\
\text { pessoal dos } \\
\text { empreendedores }\end{array}$ & & $x \quad x$ & $x \quad x$ & - & - & - & - & - & - & $\begin{array}{l}\text { Morada da } \\
\text { Floresta }\end{array}$ & - & - \\
\hline $\begin{array}{l}\text { Climate } \\
\text { Ventures }\end{array}$ & $\begin{array}{l}\text { Bons Negócios } \\
\text { pelo Clima }\end{array}$ & Rede de mentores & $x \times x$ & $x \times x$ & $x \times$ & $\begin{array}{l}\text { Agryo; } \\
\text { Inocas. }\end{array}$ & $\begin{array}{l}\text { Manioca; } \\
\text { Hakkuna. }\end{array}$ & - & $\begin{array}{l}\text { Litro de Luz; } \\
\text { Orbita; } \\
\text { Prosumir; } \\
\text { Sunne Energias } \\
\text { Renováveis. }\end{array}$ & - & $\begin{array}{l}\text { Água V; } \\
\text { Lia Marinha; } \\
\text { Pluvi.on; } \\
\text { Safe Drinking } \\
\text { Water; } \\
\text { Stattus4, }\end{array}$ & $\begin{array}{l}\text { Boomera; } \\
\text { Evolve; } \\
\text { Homebiogás. }\end{array}$ & $\begin{array}{l}\text { Bynd; } \\
\text { eflow. }\end{array}$ & - \\
\hline Din4mo & Din4mo & $\begin{array}{l}\text { Desenvolvimento } \\
\text { da gestão }\end{array}$ & & $x \quad x$ & $x \quad x$ & $\begin{array}{l}\text { Café Apuí } \\
\text { Agroflorestal }\end{array}$ & Mr. Veggy & - & - & $\begin{array}{l}\text { Genecoin; } \\
\text { Nucleário; } \\
\text { Movimento 90. }\end{array}$ & Pluvion & $\begin{array}{l}\text { Coletando; } \\
\text { Fechando Ciclo; } \\
\text { Recicleiros. }\end{array}$ & - & - \\
\hline $\begin{array}{l}\text { Fundação } \\
\text { Telefônica }\end{array}$ & $\begin{array}{l}\text { Pense Grande } \\
\text { Incubação }\end{array}$ & $\begin{array}{l}\text { Desenvolvimento } \\
\text { pessoal dos } \\
\text { empreendedores }\end{array}$ & $x \quad x$ & $x$ & & Cooltivando & - & Organifica & - & - & - & - & - & - \\
\hline Instituto Legado & Projeto Legado & $\begin{array}{l}\text { Desenvolvimento } \\
\text { da gestão }\end{array}$ & & $x \quad x$ & $x \quad x$ & Olha o Peixe! & - & $\begin{array}{l}\text { Eco Angels; } \\
\text { So+ma. }\end{array}$ & - & - & - & Badu Design & - & - \\
\hline & $\begin{array}{l}\text { Aceleração } \\
\text { Focada }\end{array}$ & $\begin{array}{l}\text { Desenvolvimento } \\
\text { da gestão }\end{array}$ & $x \quad x$ & $\times x$ & $\mathrm{x}$ & - & - & Reconectta & - & - & - & GAIA Social & - & - \\
\hline $\begin{array}{l}\text { Instituto } \\
\text { Quintessa }\end{array}$ & $\begin{array}{l}\text { Programa de } \\
\text { Aceleração }\end{array}$ & $\begin{array}{l}\text { Desenvolvimento } \\
\text { da gestão }\end{array}$ & & & $x \quad x$ & Cromai & $\begin{array}{l}\text { Fazu; } \\
\text { Fruta } \\
\text { Imperfeita; } \\
\text { Mr.Veggy; } \\
\text { Muda Meu } \\
\text { Mundo. } \\
\end{array}$ & - & EMAP Solar & - & - & $\begin{array}{l}\text { Boomera; } \\
\text { Instituto Muda; } \\
\text { Meu Copo Eco; } \\
\text { Recicleiros; } \\
\text { So+ma. } \\
\end{array}$ & $\begin{array}{l}\text { Courri; } \\
\text { E-moving. }\end{array}$ & $\begin{array}{l}\text { Já Fui Mandioca; } \\
\text { Nossa Nova. }\end{array}$ \\
\hline ITGC & $\begin{array}{l}\text { Programa de } \\
\text { Incubação da } \\
\text { ITCG }\end{array}$ & Rede de mentores & $x \times x$ & $x \times x$ & $x \quad x$ & - & - & - & LiteMe & PlantVerd & - & - & - & - \\
\hline $\begin{array}{l}\text { Kaeté } \\
\text { Investimentos }\end{array}$ & FIP Amazônia & $\begin{array}{l}\text { Investimento e } \\
\text { financiamento }\end{array}$ & & & $x \quad x$ & $\begin{array}{l}\text { Dom Porquito; } \\
\text { Ouro Verde } \\
\text { Amazônia; } \\
\text { Peixes da } \\
\text { Amazônia; }\end{array}$ & - & - & - & - & - & - & - & - \\
\hline Kviv & Kviv Ventures & $\begin{array}{l}\text { Conexão com } \\
\text { potenciais clientes } \\
\text { e parceiros }\end{array}$ & & & $x \quad x$ & - & Life Mix & - & - & - & - & - & - & - \\
\hline Libria & Projeto Libria & $\begin{array}{l}\text { Capacitação e } \\
\text { treinamento }\end{array}$ & $x \times x$ & $x \quad x$ & & - & - & - & ETM & - & Geráguas & - & - & - \\
\hline $\begin{array}{l}\text { Mov } \\
\text { Investimentos }\end{array}$ & $\begin{array}{l}\text { Mov } \\
\text { Investimentos }\end{array}$ & $\begin{array}{l}\text { Desenvolvimento } \\
\text { da gestão }\end{array}$ & & & $x \quad x$ & Audsat & - & - & $\begin{array}{l}\text { Órigo; } \\
\text { Sollar. }\end{array}$ & Biofílica & - & Triciclos & - & - \\
\hline Nesst & Nesst Portfolio & $\begin{array}{l}\text { Desenvolvimento } \\
\text { da gestão }\end{array}$ & & $x \quad x$ & $x \quad x$ & Encauchados & - & - & - & - & - & Retalhar & Pedala & - \\
\hline Papel Solidário & $\begin{array}{l}\text { Membership } \\
\text { Rede Papel } \\
\text { Solidário } \\
\end{array}$ & $\begin{array}{l}\text { Desenvolvimento } \\
\text { da gestão }\end{array}$ & $x \times x$ & $x \times x$ & $x \times$ & - & - & - & - & - & - & $\begin{array}{l}\text { Gaia Social; } \\
\text { Recicleiros. }\end{array}$ & - & - \\
\hline $\begin{array}{l}\text { Parceiros pela } \\
\text { Amazônia }\end{array}$ & $\begin{array}{l}\text { Programa de } \\
\text { Aceleração }\end{array}$ & $\begin{array}{l}\text { Desenvolvimento } \\
\text { da gestão }\end{array}$ & $x \times x$ & $x \times x$ & $x \quad x$ & $\begin{array}{l}\text { Broto; } \\
\text { Coopmel; } \\
\text { ManejeBem; } \\
\text { OKA Juice; } \\
\text { Tipiti. }\end{array}$ & $\begin{array}{l}100 \% \\
\text { Amazônia; } \\
\text { Chocolates de } \\
\text { Mendes; } \\
\text { Manioca; } \\
\text { Onisaraa; } \\
\text { Peabiru; } \\
\text { Taberna da } \\
\text { Amazônia. } \\
\end{array}$ & $\begin{array}{l}\text { Academia } \\
\text { Amazônia } \\
\text { Ensina }\end{array}$ & $\begin{array}{l}\text { Pratika } \\
\text { Engenharia }\end{array}$ & $\begin{array}{l}\text { Awí; } \\
\text { Cacauway; } \\
\text { CODAEMJ; } \\
\text { cOEXCarajs; } \\
\text { Encauchados; } \\
\text { Na Floresta. }\end{array}$ & - & $\begin{array}{l}\text { Ecopainéis do } \\
\text { Açal; } \\
\text { Raçầ+; } \\
\text { Sustente } \\
\text { Ecosoluções. }\end{array}$ & NavegAM & - \\
\hline $\begin{array}{l}\text { Positive } \\
\text { Ventures }\end{array}$ & $\begin{array}{l}\text { Venture Capital } \\
\text { de Impacto }\end{array}$ & $\begin{array}{l}\text { Investimento e } \\
\text { financiamento }\end{array}$ & & $x \quad x$ & $x$ & - & - & - & - & - & - & Eureciclo & - & - \\
\hline Rise Ventures & Venture Building & $\begin{array}{l}\text { Desenvolvimento } \\
\text { da gestão }\end{array}$ & & $x$ & $x \quad x$ & - & Beleaf & - & Alba Energia & - & - & Okena & - & - \\
\hline Sebrae/MDIC & $\begin{array}{l}\text { InovAtiva de } \\
\text { Impacto }\end{array}$ & $\begin{array}{l}\text { Captação e } \\
\text { treinamento }\end{array}$ & $x \quad x$ & $x \times x$ & $x \quad x$ & - & - & - & - & - & $\begin{array}{l}\text { Drops of } \\
\text { Amazon }\end{array}$ & $\begin{array}{l}\text { 5Rs } \\
\text { Reciclagem; } \\
\text { Coletando; } \\
\text { Eco Panplas; } \\
\text { meunRsiduo; } \\
\text { Recicli; } \\
\text { VG Residuos. }\end{array}$ & - & - \\
\hline Sebrae-RS & Programa AGIR & Rede de mentores & $x \quad x$ & $x \times x$ & $x$ & - & Sumá & Químea & - & Sintecsys & Químea & $\begin{array}{l}\text { Colibrii; } \\
\text { Ecossouvenir; } \\
\text { Re-ciclo. } \\
\end{array}$ & $\begin{array}{l}\text { Loop Bike } \\
\text { Sharing }\end{array}$ & - \\
\hline Sistema B & $\begin{array}{l}\text { Certificação } \\
\text { de Empresas B }\end{array}$ & $\begin{array}{l}\text { Reconhecimento e } \\
\text { divulgação }\end{array}$ & $x \quad x$ & $x \times x$ & $x \quad x$ & $\begin{array}{l}\text { Agrotools; } \\
\text { Daterra } \\
\text { Coffee; } \\
\text { Fazenda da } \\
\text { Toca; } \\
\text { Jucaia; } \\
\text { SanCoffee. }\end{array}$ & $\begin{array}{l}\text { AMMA } \\
\text { Chocolates; } \\
\text { Dengo } \\
\text { Chocolates; } \\
\text { Olivia Saladas; } \\
\text { Teva; } \\
\text { Zanlorenzi } \\
\text { Bebidas. }\end{array}$ & $\begin{array}{l}\text { eCycle; } \\
\text { Reconectta. }\end{array}$ & $\begin{array}{l}\text { COMBIO; } \\
\text { Sunew: } \\
\text { Tecvolt. }\end{array}$ & - & - & $\begin{array}{l}\text { Arueira } \\
\text { Ambiental; } \\
\text { Boomera; } \\
\text { Dinâmica } \\
\text { Ambiental; } \\
\text { Eco Panplas; } \\
\text { MateriaBrasil; } \\
\text { Meu Copo Eco; } \\
\text { Okena; } \\
\text { Parangolé; } \\
\text { Recicladora } \\
\text { Urbana; } \\
\text { Rede Asta; } \\
\text { Retalhar; } \\
\text { Selletiva; } \\
\text { Triciclos; } \\
\text { YouGreen. }\end{array}$ & Courri & $\begin{array}{l}\text { Biowash; } \\
\text { Insecta Shoes; } \\
\text { Natura; } \\
\text { Papel Semente; } \\
\text { Positiv.a. }\end{array}$ \\
\hline Sitawi & $\begin{array}{l}\text { Fundo } \\
\text { Socioambiental } \\
\text { Rotativo }\end{array}$ & $\begin{array}{l}\text { Investimento e } \\
\text { financiamento }\end{array}$ & & $\mathrm{x}$ & $x \quad x$ & Inocas & Coperjunho & - & Ecoservice & AMATA & - & Rede Asta & - & - \\
\hline Unisinos & $\begin{array}{l}\text { Prêmio Roser } \\
\text { Unitec }\end{array}$ & Rede de mentores & $x \times x$ & $x \times x$ & $x \times$ & Silo Verde & - & - & & - & - & & - & - \\
\hline Yunus \& Youth & $\begin{array}{l}\text { Fellowship } \\
\text { Program }\end{array}$ & $\begin{array}{l}\text { Rede entre } \\
\text { empreendedores }\end{array}$ & $x$ & $x \times x$ & $x$ & Thinkmilk & - & - & Litro de Luz & - & - & Retalhar & - & - \\
\hline $\begin{array}{l}\text { Yunus Negócios } \\
\text { Sociais }\end{array}$ & $\begin{array}{l}\text { Yunus Negócios } \\
\text { Sociais }\end{array}$ & $\begin{array}{l}\text { Investimento e } \\
\text { financiamento }\end{array}$ & & $\mathrm{x}$ & x & - & - & - & - & Assobio & - & Instituto Muda & - & - \\
\hline
\end{tabular}

Fonte: Elaboração própria a partir do website das organizações.

Nota:
(*)1) fase das ideias; 2) validação: foco no cliente; 3) validação: foco no produto; 4) validação: foco no mercado; 5) refinamento do modelo de negócio; e 6) expansão. 


\section{REFERÊNCIAS}

ANDE - Aspen Network of Development Entrepreneurs; BOTICÁRIO - Fundação Grupo Boticário de Proteção à Natureza. Spotlight setorial: investimentos de impacto em conservação da biodiversidade. 2018. Disponível em: <https://cdn.ymaws. com/www.andeglobal.org/resource/resmgr/brazil_files/AF_ASPEN_Spotlight_Biodivers.pdf $>$. Acesso em: 18 jun. 2020.

ANDE - Aspen Network of Development Entrepreneurs; LAVCA - Latin American Venture Capital Association. Mapa do setor de investimento de impacto no Brasil. 2014. Disponível em: <https://assets.aspeninstitute.org/content/uploads/files/ content/upload/AF_resumo_aspen_portugues_eqom.pdf>. Acesso em: 18 jun. 2020.

ANDE - Aspen Network of Development Entrepreneurs; LAVCA - Latin American Venture Capital Association. Panorama do setor de investimento de impacto na América Latina. 2016. Disponível em: <https://cdn.ymaws.com/www.andeglobal.org/ resource/resmgr/docs/LatAm_ImpInv_Spanish_2016.pdf>. Acesso em: 18 jun. 2020.

ANDE - Aspen Network of Development Entrepreneurs; LAVCA - Latin American Venture Capital Association. Panorama do setor de investimento de impacto no Brasil. 2018. Disponível em: <https://cdn.ymaws.com/www.andeglobal.org/resource/ resmgr/brazil_files/AF_ASPEN_Summary_NAC_Brasil_.pdf $>$. Acesso em: 18 jun. 2020.

BRASIL. Decreto 9.977, de 19 de agosto de 2019. Dispõe sobre a Estratégia Nacional de Investimentos e Negócios de Impacto e o Comitê de Investimentos e Negócios de Impacto. Casa Civil, Subchefia para Assuntos Jurídicos, 2019. Disponível em: <http://www.planalto.gov.br/ccivil_03/_ato2019-2022/2019/decreto/D9977.htm>. Acesso em: 18 jun. 2020.

BRASIL. Lei Complementar 123, de 14 de dezembro de 2006. Institui o Estatuto Nacional da Microempresa e da Empresa de Pequeno Porte. Casa Civil, Subchefia para Assuntos Jurídicos, 14 dez. 2006. Disponível em: <http://www.planalto.gov.br/ ccivil_03/leis/lcp/lcp123.htm>. Acesso em: 18 jun. 2020.

CAMPOS, Fernando.; COMINI, Graziella. Negócios com impacto ambiental. In: BARKI, E.; COMINI, G. M.; TORRES, H. G. (eds.). Negócios de impacto socioambiental no Brasil: como empreender, financiar e apoiar. 1. ed. Rio de Janeiro: Editora FGV, 2019, p. 247-268.

CASTRO, Bianca; FARES, Lucas; GONÇALVES, Rodrigo; YOUNG, Carlos. Avaliação das fontes potenciais de financiamento para projetos de caráter ambiental relacionados aos ODS no Brasil. Revista Iberoamericana de Economía Ecológica, v. 31, n. 1, p. 29-45, 2019.

CLIMATE VENTURES. Visão geral da $1^{\text {a }}$ chamada Bons Negócios pelo Clima. 2018. Disponível em: <https://static1. squarespace.com/static/5bbbd7c7a9ab95657472072f/t/5bf54ec74ae2376294e54c38/1542803165183/\%5BCVentures\%5D +Infografia_AF_12nov2018_FO.pdf $>$. Acesso em: 18 jun. 2020.

CLIMATE VENTURES. Visão geral da 2a chamada Bons Negócios pelo Clima. Climate Ventures, 2020 [no prelo].

CONEXSUS. Mapa de negócios comunitários sustentáveis. 2019. Disponível em: <https://desafioconexsus.org/mapa-desafioconexsus/>. Acesso em: 18 jun. 2020.

COPPOLA, Beatriz; SANT’ANA, Diogo. Negócios de impacto e a atuação econômica das organizações da sociedade civil. Boletim de Análise Político-Institucional: Organizações da Sociedade Civil no Brasil, 2019. Disponível em: <http://www.ipea. gov.br/portal/images/stories/PDFs/boletim_analise_politico/190717_bapi_20.pdf>. Acesso em: 18 jun. 2020.

DISSEMOND, Leonie; ITO, Nobuiuki; KAETSU, Patricia; ROTONDARO, Angelica. Market assessment about impact investing in climate-smart agriculture in Brazil. Alimi Impact Ventures, 2018. Disponível em: <http://www.climatesmart.com. br/Impact_Investing_in_ClimateSmart_Agriculture.pdf>. Acesso em: 18 jun. 2020.

EPE - Empresa de Pesquisa Energética. Balanço energético nacional 2019: ano base 2018. Rio de Janeiro. 2019. Disponível em: 〈http://www.epe.gov.br/pt/publicacoes-dados-abertos/publicacoes/balanco-energetico-nacional-2019>. Acesso em: 18 jun. 2020.

FAO - Food and Agriculture Organization of the United Nations. Climate-smart agriculture sourcebook on climate-smart agriculture, forestry and fisheries. United Nations (FAO), 2013. Disponível em: 〈http://www.fao.org/3/a-i3325e.pdf〉. Acesso em: 18 jun. 2020.

FEITOSA, Cintya; FONSECA, Marcus; MENDONÇA, Hudson; VIEIRA, Vanessa. Mapeamento do ecossistema de startups de cleantech no Brasil. ABStartups, COPPE/UFRJ, EDP, FGVces, 2019. Disponível em: <http://mediadrawer.gvces.com.br/ publicacoes-2/original/ecossistema-de-startups-de-cleantech-no-brasil.pdf>. Acesso em: 18 jun. 2020.

GIFE - Grupo de Institutos, Fundações e Empresas. Censo GIFE 2016. 2017. Disponível em: <https://sinapse.gife.org.br/ download/censo-gife-2016>. Acesso em: 18 jun. 2020.

GIFE - Grupo de Institutos, Fundações e Empresas. Censo GIFE 2018. 2019. Disponível em: <https://sinapse.gife.org.br/ download/censo-gife-2018>. Acesso em: 18 jun. 2020. 
ICE - Instituto de Cidadania Empresarial; PIPE SOCIAL. O que são negócios de impacto. 2019. Disponível em: <https:// forcatarefa-assets.s3.amazonaws.com/uploads/2019/11/ICE-Estudo_Negócios-de-Impacto-2019_Web.pdf〉. Acesso em: 18 jun. 2020.

KACHAN. Cleantech redefined. 2013. Disponível em: <http://www.kachan.com/cleantech-redefined/>. Acesso em: 18 jun. 2020.

MARCHESIN, Giselle; MONTES, Heloisa; SAMPAIO, Marina; SOUZA, Elias; VALENTE, Eduardo. Pesquisa de intermediários do ecossistema de finanças sociais e negócios de impacto. 2015. Disponível em: <https://forcatarefa-assets.s3.amazonaws. com/uploads/2015/10/MapeamentoIntermediarios.pdf>. Acesso em: 18 jun. 2020.

OLIVEIRA FILHO, Gilberto; IZZO, Daniel. Buscando recursos financeiros. In: BARKI, E.; COMINI, G. M.; TORRES, H. DA G. (eds.). Negócios de impacto socioambiental no Brasil: como empreender, financiar e apoiar. 1. ed. Rio de Janeiro: FGV, 2019, p. 187-214.

PIPE SOCIAL. $1^{\circ}$ Mapa de negócios de impacto social + ambiental. 2017. Disponível em: 〈https://www.pipe.social/mapa2017〉. Acesso em: 18 jun. 2020.

PIPE SOCIAL. $2^{\circ}$ Mapa de negócios de impacto social + ambiental. 2019. Disponível em: <https://www.pipe.social/ mapa2019>. Acesso em: 18 jun. 2020.

PIPE SOCIAL. Scoring de investimentos de impacto. 2020. Disponível em: <https://pipe.social/produtos/produtos/scoringde-impacto>. Acesso em: 18 jun. 2020

PNUD - Programa das Nações Unidas para o Desenvolvimento; SEBRAE - Serviço Brasileiro de Apoio às Micro e Pequenas Empresas. Retrato dos pequenos negócios inclusivos e de impacto no Brasil 2017. 2017. Disponível em: <https://www.br.undp. org/content/dam/brazil/docs/publicacoes/prosperidade/3-Pequenos-Negocios-Inclusivos-e-de-Impacto-no-Brasil.pdf>. Acesso em: 18 jun. 2020.

QUINTESSA - Instituto Quintessa. Guia para o desenvolvimento de negócios de impacto: Guia 2.5. 2017. Disponível em: 〈http://www.guiadoisemeio.com.br〉. Acesso em: 18 ago. 2019.

SEBRAE - Serviço Brasileiro de Apoio às Micro e Pequenas Empresas. Engajamento dos pequenos negócios brasileiros em sustentabilidade e aos ODS. 2018. Disponível em: 〈http://sustentabilidade.sebrae.com.br/Sustentabilidade/Parasua empresa/ Publicações/Pesquisa Engajamento_WEB (1).pdf>. Acesso em: 18 jun. 2020.

STAHEL, Walter. The circular economy. Nature News, v. 531, n. 7595, p. 435-438, 2016. 


\section{O AUTOR}

\section{Julio Nunes Campos \\ julio.nunes.campos@gmail.com}

Graduado em economia (ESALQ/USP), mestrando em desenvolvimento econômico (IE/UNICAMP), com experiência em gestão de projetos em negócios de impacto e no terceiro setor. Desenvolve pesquisas com organizações sociais e análise institucional aplicada a questões ambientais. 


\title{
artigos GIFE
}

Supervisão: José Marcelo Zacchi e Gustavo Bernardino

Coordenação: Carolina Magosso

Produção editorial: Gleice Regina Guerra

Apoio: Graziela Santiago

Comitê de seleção: Ana Lúcia D'Império Lima, Fábio Stlva Tsunoda, Laura Leal e Lívia Menezes Pagotto

Diagramação: Alastra, Comunica.

Impressão: Forma Certa

ISSN: 2674-8061

DOI: doi.org/10.33816/gife.20200202a3

(c) 2020 GIFE - Grupo de Institutos Fundações e Empresas

\section{(C) (i) ()}

Este material é disponibilizado sob a licença Creative Commons Atribuição Não Comercial 4.0 Internacional. http://creativecommons.org/licenses/by-nc/4.0

As opiniões e análises expressas nesta publicação não necessariamente refletem as do GIFE.

\author{
Apoio institucional \\ Alana \\ Ford Foundation \\ Fundação Bradesco \\ Fundação Lemann \\ Fundação Tide Setubal \\ Instituto Unibanco \\ Laudes Foundation
}

